\section{The effect of efference to the arm on visual adaptation to curvature: A replication}

\author{
JOHN W. GYR and RICHMOND WILLEY \\ The University of Michigan, Ann Arbor, Mich. 48104
}

Ss inspected a curved line through a prism that made it appear straight, then moved one finger along the line in one of two ways. One way encouraged the learning of a new efferent program for a curved movement (learning). The other (accuracy) offered little opportunity for such learning. Replicating a finding by Festinger, Burnham, Ono, \& Bamber (1967), the learning condition produced slightly, but significantly, more visual adaptation to curvature than did the accuracy condition. There was some suggestion that greater prismatic strength produced greater adaptation. The results support the idea that efferent commands to the arm can affect visual perception of contour shape.

An important series of studies reported by Festinger, Burnham, Ono, \& Bamber (1967) support the idea that efference is involved in the adaptation to distortions of contours caused by prisms. Festinger et al argue that visual adaptation depends on reestablishing new efferent-afferent correlations in the visual system. According to this theory, it is possible to effect visual adaptation by altering in a systematic fashion the normal correlation between efferent output and afferent input. For example, suppose a $S$ wearing contact lenses with prisms mounted on them looks at a curved line that appears straight. To scan this line, he soon finds out that in order to keep the line centered on the fovea, the usual correlation between straight-line scanning of an apparently straight line and foveal centering of that line no longer obtains. In order to maintain the former invariance between foveal centering of an optically straight line and movement, efference leading to straight-line motion has to give way to efference, which causes the eye to move along a curved path. The theory holds that the resulting readiness to respond to straight-line inputs by movements, which in the past have been appropriate to a curved contour, leads to a recoding of these inputs: the optically straight will be seen as curved, and adaptation results.

It has been proposed that the apparent conflict between an established local sign (a straight retinal projection) and a newly found efferent-afferent correlation (which now involves making curved motions in order to keep an optically straight line in focus) may be resolved by altering the proprioceptive interpretation of the moevement. This would lead to a feeling that the physically curved motion of the eye is straight. Such an interpretation is favored by Harris (1965). Notice that under such conditions no visual adaptation would be expected. Festinger et al, however, take the view already presented, i.e., that the learning of a new efferent-afferent correlation takes place, which will in fact lead to a recoding of visual local signs and, hence, to visual adaptation. In their experiments they compare conditions in which there is contour-specific efference with those in which, in regard to contour, there is only proprioception. They predict visual adaptation for the former but not for the latter.

Festinger et al (1967) consider the efference which may affect visual adaptation not to be limited to efference due to movement of the eye, but to include movement of the arm in regard to a visually viewed input. In three of four experiments reported, the authors studied the influence exerted on visual adaptation by contour-specific efference correlated with arm movement. Specifically, in one part of their second reported experiment, Ss viewed through a prism an apparently straight, but physically curved, set of two parallel rods. In the efferent, or so-called learning condition, Ss had to move a stylus between the rods without touching them, making a smooth sweeping motion. This condition was designed to maximize the likelihood of a particular contour-specific efferent command to the arm being made repeatedly. In the nonefferent, or so-called accuracy condition, Ss moved down one of the parallel rods, keeping his stylus in constant contact with the rod. The authors assumed that this condition would particular way and, hence, would minimize contour-specific efference. Although the reported effects in this particular experiment were relatively small, the authors did demonstrate significantly greater adaptation in the learning (efferent) condition than in the accuracy (non-efferent) condition.

The purpose of the present study was to make a somewhat more stringent demand on the Festinger theory by exploring minimize the need to direct the arm in a whether the qualitative effect demonstrated by Festinger could be manipulated quantitatively. Specifically, by using a 25 -diopter prism, Festinger et al created a given perceptual distortion and, hence, a given level of conflict between vision and efference from the arm. The study to be reported here explored the effect on adaptation of increasing or decreasing this conflict between efference from the arm and visual information through the eyes by studying the amount of adaptation when prisms of $55,30,20$ diopters were used. Moreover, these conditions are also contrasted with the amount of adaptation under the so-called accuracy condition. That is, since it is assumed that in the accuracy condition there is little or no contour-specific efference to the arm, there will also be practically no conflict between efference to the arm and input through the eyes. Hence, under the accuracy condition, adaptation whould be minimal for any diopter value. The hypothesis to be tested, therefore, is that adaptation will be strongest in the 55-diopter case, followed by the 30,20 , and accuracy conditions, in that order.

\section{SUBJECTS}

The Ss were female students at the University of Michigan. Twelve Ss were used in each of four experimental conditions.

The apparatus was patterned after that used by Festinger, Burnham, Ono, \& Bamber (1967) in Experiments 1 and 2. Either a single brass rod, $1 / 8$ in. in diam, or two such rods, parallel to each other and $1 / 2$ in. apart, could be mounted vertically against a white formica background. The rods were held in place by brackets and, hence, were free to slip up and down. By turning a knob, the rods could be made to curve. The rods were viewed from a distance of about $40 \mathrm{~cm}$, and the visible portion of the rods was restricted to about $37 \mathrm{~cm}$. The visual angle subtended by the test rods was about $40 \mathrm{deg}$.

Principal differences from the apparatus used by Festinger et al were as follows. (1) The viewing apparatus was not a set of goggles, but a modified stereoscope hood, into which prisms could be inserted. This hood was attached rigidly to the apparatus, thus eliminating the need for a biteboard. (2) To bend the rods, pressure was not applied at a single point at their center, but at two points, each 2 in. inward from the fixed brackets. Since the distance between the fixed brackets $(66 \mathrm{~cm})$ was the same as in Festinger's apparatus, measurements of the deviation of the center of the rods from true straight were comparable to Festinger's. 
Table 1

Mean Changes (in Centimeters) in Settings of Straightness*

\begin{tabular}{|c|c|c|c|c|}
\hline & \multicolumn{4}{|c|}{ Experimental Condition } \\
\hline & \multicolumn{3}{|c|}{ Learning } & \multirow{2}{*}{$\begin{array}{l}\text { Accuracy } \\
30 \text { Diopter }\end{array}$} \\
\hline & 55 Diopter & 30 Diopter & 20 Diopter & \\
\hline Change with Prisms & $\frac{.333}{(.296)}$ & $\begin{array}{c}\frac{.192}{(.296)} \\
4 \%\end{array}$ & $\frac{.011}{(.361)} \frac{0 \%}{0 \%}$ & $\begin{array}{c}\frac{.010}{(.298)} \\
0 \%\end{array}$ \\
\hline Change with Naked Eye & $\begin{array}{l}\frac{.162}{(.324)} \\
2 \%\end{array}$ & $\begin{array}{c}\frac{.353}{(.302)} \\
7 \%\end{array}$ & $\begin{array}{l}\frac{.112}{(.298)} \\
3 \%\end{array}$ & $\begin{array}{c}-\frac{.003}{(.390)} \\
07 c\end{array}$ \\
\hline Mean Combined Change & $\frac{.246}{(.224)}$ & $\frac{.276}{(.210)}$ & $\frac{\left.\frac{.061}{254}\right)}{1 \%}$ & $\begin{array}{c}\frac{.003}{(.303)} \\
0 \%\end{array}$ \\
\hline
\end{tabular}

*Underlined figures represent mean changes. Figures in parentheses are standard deviations. Figures in brackets indicate percent change relative to the initial setting of apparently straight.

\section{PROCEDURE}

Pre- and posttests were the same as employed by Festinger et al. In the pretest, $S$ first viewed the rod with the naked eye and adjusted it four times so that it appeared straight. Four comparable settings were then made while looking through a prism. The posttest procedure was identical except that the prism settings were made first. It was emphasized that settings should be made on the basis of appearance, rather than by intellectual calculation or estimation of true shape.

Certain other features of the procedure were common to all conditions. Viewing was always with the left eye only. The prism was base-left, which means that an apparently straight line is actually concave-left. Prior to training, the prism was inserted and the rod was set at the average of S's pretest measurements with the prism. Hence, during the training, the rod was always apparently straight and should not have given rise to any adaptation of the type noted by Gibson (1933). Total training time was $25 \mathrm{~min}$. This was divided into five blocks of $5 \mathrm{~min}$ each, alternating with $1 \frac{1}{2}$-min rest periods, during which S's eyes were closed. Each block consisted of 50 6-sec trials.

There were three conditions designed to maximize reliance on contour-specific efference. These conditions differed only in the strength of the prism employed. The prisms used were 20,30 , and 55 diopters; the angles of deviation were about 11,17 , and $29 \mathrm{deg}$, respectively. The prism was mounted such that the side parallel to the viewing surface was furthest away from the eye. Especially with powerful prisms, this increases the angle of deviation. The 55-diopter prism was obtained by superimposing prisms of 15 and 20 diopters. In a fourth condition a 30-diopter prism was used, and the training was designed to minimize reliance on efference. The efference conditions departed significantly from Festinger's procedure, as preliminary trials with a different method looked more promising. In the present procedure only one rod was used, instead of two, and $S$, rather than rapidly moving a stylus between two rods, tried to move her index finger so as to replicate the curvature of the rod without either touching or seeing it. It was reasoned that this procedure would impose less physical constraint on the movement of the hand and, hence, more need to rely on accurate efferent direction of its path. At the beginning of a trial, $S$, with her eyes closed, placed her right index finger against the board and then slid it up and to the left until it hit the place where the rod intersected the upper inner bracket. She then moved her finger downward, attempting to keep close to the rod without touching it and to end at the point where the rod intersected the lower inner bracket. The vertical distance moved was thus $56 \mathrm{~cm}$; this was greater than the visible portion of the rod. After the stroke, she opened her eyes for the first tima and looked at the rod for about $1 \mathrm{sec}$. She then closed her eyes again, rested her hand, and waited for the next signal. The $S$ could tell by touch how close she had come to ending at the lower intersection. In addition, whenever her path deviated from the rod by more than about $1 \mathrm{in}$. at the center, the $\mathrm{E}$ told her to move closer. The Ss rapidly learned to perform accurately at a speed of about $1 \mathrm{sec}$ per stroke; most Ss were performing well by the end of the first block of 50 trials. The Ss were allowed to hold the finger against the rod for the first few trials but were required to move without touching it after no more than 25 trials.

In the nonefference condition, $\mathrm{S}$ moved her finger along the rod, continuously touching it for all of the 250 trials. Otherwise, the procedure was the same as that used in the learning condition. This procedure was basically the same as the nonefference condition in Experiment II of
Festinger et al except that $S$ was required to move according to a timed schedule, rather than at her own pace.

\section{RESULTS}

The findings are summarized in Table 1 , which gives mean changes from pre- to posttests in settings of straightness. A positive change is a change in the direction of adaptation.

(1) F ratios were computed both within the learning condition alone and for the combined learning-accuracy data. Within the learning condition alone, no $F$ test achieves quite the acceptable level of significance. The ratios for change with prisms, $F(2,33)=3.06$, and for the mean combined prism and naked-eye change, $F(2,33)=3.08$, approach, but do not reach, the value of 3.33 required for the .05 level.

The ratios for combined learning and accuracy conditions for change with prisms and for the mean combined change are significant at less than the .05 level; $F(3,44)=2.97$ and 3.59 , respectively. The $F$ for change with the naked eye, $F(3,44)=2.41$, only approaches significance. Even though the individual entries in Table 1 are not all in the order predicted by the hypothesis, it may be concluded that there is a general quantitative relation between the degree of conflict in efference from the arm and visual input, on the one hand, and visual adaptation, on the other. It should be pointed out, parenthetically, that there is no significant interaction of prism vs naked-eye change and any of the diopter conditions within the learning condition.

(2) The data also generally replicate the findings reported by Festinger et al (1967). On an F test, pre/post changes with the prisms in the learning condition are significantly different from the accuracy-condition changes in the case of learning with the 55-diopter prism $[F(1,22)=7.07, p<.05]$, and they approach significance for the 30-diopter case $[F(1,22)=2.24, p>.10]$ but are obviously random for the 20-diopter case. Change with the naked eye, or the so-called aftereffect, is in the predicted direction, though not significant for the 55-diopter case $[F(1,22)=1.27, p>.10]$, significant for the 30-diopter case $[F(1,22)=6.24$, $\mathrm{p}<.05]$, and random for the 20-diopter condition. The mean combined change is significant both for the 55- and 30-diopter c ases $[F(1,22)=5.83$ and 7.58 , respectively, $\mathrm{p}<.05$ ] but not for the 20-diopter condition. All the entries in the learning condition in Table 1 exceed the relevant entries in the accuracy condition, as predicted by Festinger. On the whole, these results thus would seem to support and replicate Festinger's reported findings. 


\section{CONCLUSIONS}

Festinger et al (1967) have shown that efference plays a crucial role in adaptation. The hypothesis specifying a role for efference derives from considering visual perception as a process in which efference and afference become correlated. The present study tends to show that the effect of efference may be increased or decreased, depending on the degree to which contour-specific efferent feedbacks from the arm diverge from the normally visual expected local signs. Both the experiments of Festinger et al and this study show, moreover, that efference, rather than proprioception, is required for visual adaptation, at least in this kind of experimental setting. It may thus be the case that theories claiming the dominance of vision over touch (Harris, 1965; Rock, 1966) are correct as far as proprioception is concerned but may not apply when efference is involved.

\section{REFERENCES}

FESTINGER, L., BURNHAM, C. A., ONO, H., \& BAMBER, D. Efference and the conscious experience of perception. Journal of Experimental Psychology Monograph, 1967, 74, 1-37.

GIBSON, J. J. Adaptation after-effect and contrast in the perception of curved lines. Journal of Experimental Psychology, 1933, $16,1-31$.

HARRIS, C. S. Perceptual adaptation to inverted, reversed, and displaced vision. Psychological Review, $1965,72,419-444$.

ROCK, I. The nature of perceptual adaptation. New York: Basic Books, 1966.

\title{
Type of instruction, abstractness, and mnemonic system*
}

\author{
GORDON WOOD and MARTIN BOLT ${ }^{\dagger}$ \\ Michigan State University, East Lansing, Mich. 48823
}

Two experiments were conducted to determine if the effect of manipulating imagery instructions and peg list abstractness depends on whether a paired-associate or one-bun technique is used. It appears that the paired-associate and one-bun techniques yield comparable results regarding the effectiveness of imagery instructions and peg list abstractness.

Mnemonic systems have been investigated by using two different techniques. For the one-bun approach Ss are asked to memorize a series of pegs. Generally, words are used as pegs and each word is numbered, with associations between numbers and words (e.g., one-bun, two-shoe). Following the memorization of the pegs, new words can be memorized by associating each new word to a peg word (cf. Bugelski, Kidd, \& Segmen, 1968; Berla,

*This research was supported by Grant $\mathrm{MH} 16991$ from the National Institute of Mental Health. Thanks are due to Joyce Pennington. $\rightarrow$ Now at Calvin College, Grand Rapids. Michigan 49506. instructions and peg list abstractness depends on whether a PA or one-bun technique is used.

Paivio (1969) notes that manipulating imagery instructions (imagery vs verbal mediation) for PA learning has little influence on performance, but imagery instructions facilitate performance when a one-bun technique is used (cf. Paivio, 1968). Since the two approaches to the study of mnemonic systems do not yield comparable results, Paivio questions the feasibility of using the PA technique to study mnemonics. Yet, the evidence Paivio cites to support the importance of imagery instructions with a one-bun technique is less than convincing.

Paivio (1968) found that Ss told to use "mental images" to link memorized peg words with the to-be-recalled words were superior to the "nonimagery" controls. However, since the control Ss were instructed to study the words by repeating the peg word along with the to-be-recalled word, it can be argued that the control Ss received verbal repetition instructions instead of verbal mediation instructions. If Paivio compared imagery and verbal repetition instructions, the effect of type of instruction yields comparable results with a PA and a one-bun technique, since verbal repetition instructions also result in lower PA learning than verbal mediation or imagery instructions (Paivio \& Yuille, 1969). Thus, there is a lack of evidence for Paivio's assertion that the one-bun and PA techniques do not yield comparable results regarding the effectiveness of imagery instructions. The purpose of Experiment 1 was to test Paivio's view by assessing the effect of type of instruction with a one-bun technique.

\section{EXPERIMENT 1}

Method

The design was patterned after the Paivio (1968) study. Three groups were given the one-bun technique and imagery, verbal mediation, or repetition instructions. A control group was not given the one-bun technique. All Ss were given one study and test trial on each of the two 10.item lists. The experimental manipulations were made after $S$ s had completed List 1 recall. The two 10 -item lists to be recalled were constructed by selecting 20 nouns having relatively high concreteness and imagery ratings from the Paivio, Yuille, \& Madigan (1968) norms. The words were divided randomly into two lists of 10 words each, and a number from 1 to 10 was assigned to each word such that each number was used only once for each list.

A total of 52 students from undergraduate psychology courses at Michigan State University, who were not 